\title{
A SIMULATION STUDY OF THE EFFECT OF MOSQUE DESIGN ON EGRESS TIMES
}

\author{
Khaled Nassar \\ Ahmed Bayyoumi \\ The American University in Cairo \\ The American University in Cairo \\ Dept. of Construction and Architecture Engineering \\ New Cairo, EGYPT \\ Dept. of Construction and Architecture Engineering \\ New Cairo, EGYPT
}

\begin{abstract}
The Mosque prayer hall is perhaps the only architectural space designed for a large number of floorseated occupants. A critical issue in the design of mosques is determining the number and configuration of exit locations. This paper describes a discrete-event simulation model developed to assess the effect of mosque prayer hall configuration on the egress times of the occupants. The simulation model takes into consideration the behavioral aspects of the mosque occupants such as shoe placement and pickup, after prayer lingering, late egress of front rows, after prayers, and congregations inside and outside the mosque. Most of the various exit configurations possible in mosque design are modeled and assessed for total egress time as well as flow rates. It is shown that one-sided exit location out performs all other configurations. The study presents the first such analysis of mosque egress and the results should of great interest to architects and researchers alike.
\end{abstract}

\section{INTRODUCTION}

From an architectural point of view, mosques are unique facilities in that they are the only buildings where the entire space is occupied by floor-seated individuals. The occupant capacity of the mosque prayer halls is probably the highest of all building spaces. Yet international building codes (such as the International Building Code IBC) fail to specify appropriate occupant load factors for mosque prayer hall spaces. More importantly the emergency egress requirements for mosque spaces offer unique challenges especially when specifying egress number, width, configurations and type. Most if not all building codes lack specific requirements on emergency egress for mosques. The problem is exacerbated when considering mosque prayer hall designs in confined areas of larger facilities such as malls and airports, where limitations exist on the location and design of the means of egress, unlike open mosques. In addition to the emergency egress and life safety concerns, there is a very limited work done on the level of service expected in mosque facilities in general and especially at exit corridors or egress access. This often results in efficient occupant flows in and out of the mosques and places incalculable risks on the lives of the worshippers in case of disasters.

Several unique issues affect emergency egress requirements for mosques during regular and Friday prayers alike where various occupant loads are expected. For example when considering design standards and emergency egress requirements for mosques, the intermittent behavior of the occupants after the prayers (due to social exchanges) should be accounted for as well as other functional reasons such as the need to put on shoes immediately after exiting the prayer hall, which temporarily blocks the exits. Therefore, spatial and temporal behavior of the occupants therefore needs to be considered when developing design standards for mosques. In addition, several questions regarding mosque designs remain open; are 


\section{Nassar and Bayyoumi}

side exits better than the more common back exits? Is a square or a rectangular configuration better for the efficiency of the exit process and occupant flow? What is the level of service that could be expected at the exits given different exit designs? How many means of exits are required for different sized mosques? Where is the best location for ablutions areas? What is the best design for confined areas?

This research therefore aims at developing design standards for mosque designs worldwide by studying the occupant dynamics before and after prayer. Data recorded from video captured from various mosques was collected and segmented. Occupant behavior as well as arrival, and departure rates were analyzed. A comprehensive agent-based simulation model is developed that captures typical worshippers' behavior and is calibrated based on the collected data and used to carry out extensive experiments on occupant flow and exit. The outcome of this research is expected to be comprehensive design standards for mosque designs including specific emergency egress requirements. The results are expected to provide more efficient, safer and perhaps more economic mosques designs worldwide. This paper focuses mainly on the development and analysis of the simulation models used to analyze the location of the exits in terms of the efficiency and ease of egress from the prayer hall. In the next section the typical configuration of mosque prayer halls are discussed.

\section{MOSQUE PRAYER HALL CONFIGURATIONS}

There are many configurations for religious buildings and it is a difficult task to concatenate all of their spatial designs into one prototypical space. Throughout history, the mosque has taken various forms from the hypostyle to the dome mosque.

The most important space in the mosque is obviously the prayer hall, which usually takes the form of a square and/or a rectangle due to the fact that worshippers line up in equally space rows during prayers, and as such, other forms of the prayer hall such as circle or a hexagon are uncommon as they will result in lines of unequal lengths. Non-rectilinear prayer halls do exist sparingly and may have taken these forms for other reasons; the circular Hagia Sofia in Turkey being the most notable since it was originally built as a church. However in today's mosques, there seems to be one particular configuration that is recurring; that is the bilateral symmetry space with four columns often carrying a significant feature such as a dome. Figure 1 shows a simplification of the main mosque forms which have been built in the Gulf region within the last 30 years.

There are various factors that affect the pedestrian/occupant movements including the doors orientations, doors width, area in front of the door inside the mosque, area in front of the doors outside the mosque, and the mosque orientation in relation to the parking area. A number of exit location configurations options can be identified for a typical prayer hall. Exists can be located on the back end of the prayer hall, on the sides of the prayer hall of to one side only. The location of the exit will have a significant impact on the performance of the design in terms of ease, safety and efficiency of the egress of the occupants from the prayer hall. This is usually a very significant issue (Figure 2) and may become a safety issue in some cases where the mosque/prayer hall is located in a location with restricted access such as malls or airports. 


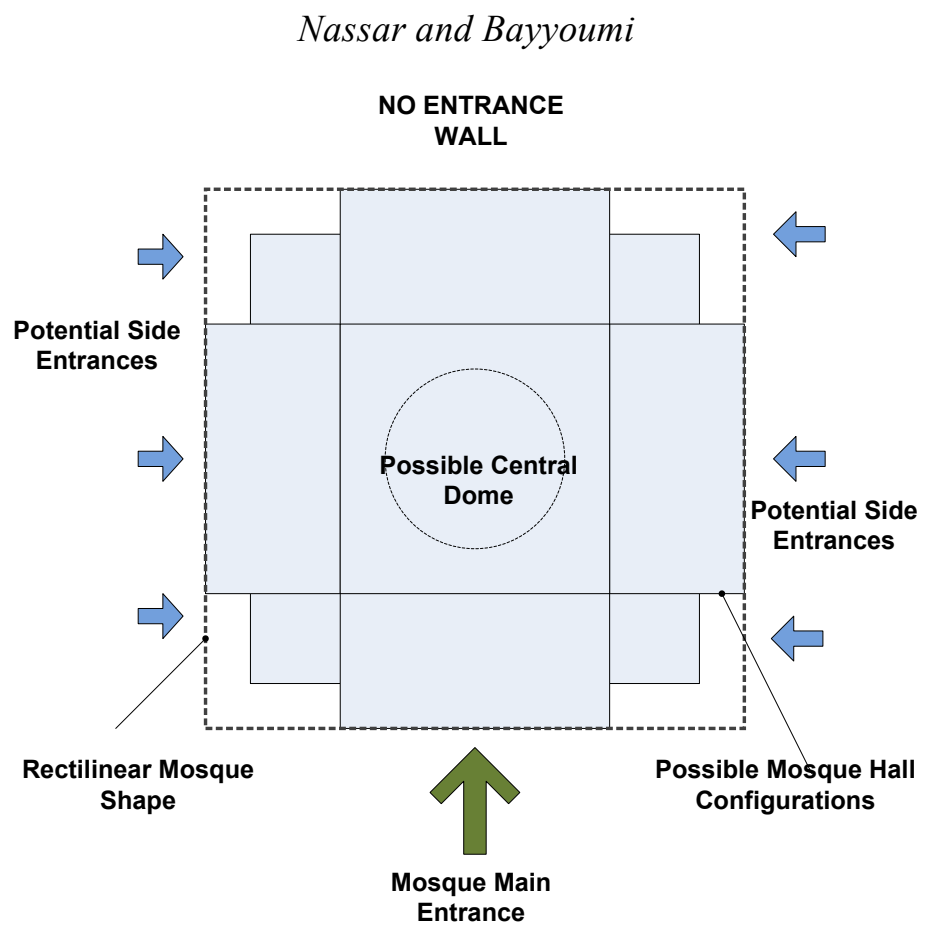

Figure 1: Sample Mosque Prayer Hall Configurations

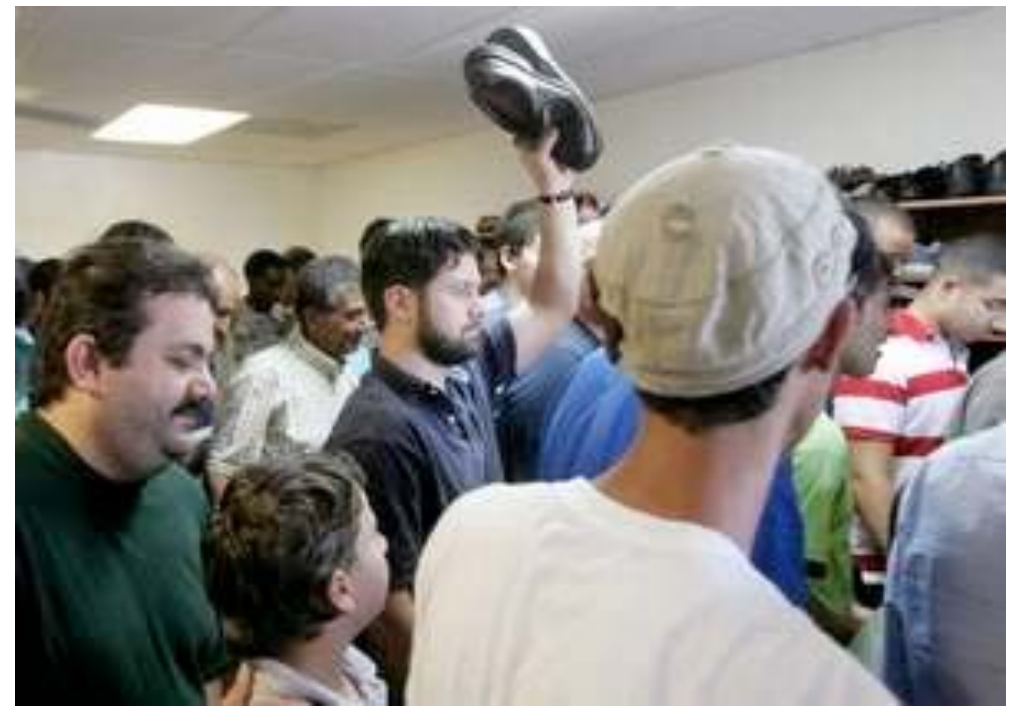

Figure 2: Crowding at mosque exists

Specifically, this research considered a typical prayer hall with nine different configurations of the exits. The exit configurations represent the most common layouts of doors in the mosque prayer hall. Each of the nine exit configurations is modeled with an attached area on the outside and inside to represent crowding areas and allow for occupant densities to be measured. Figure 3 shows the nine different configurations. Each of these configurations will be assessed to identify which provides the most efficient layout of exits under typical egress behavior of worshippers in the mosque, as explained next. 


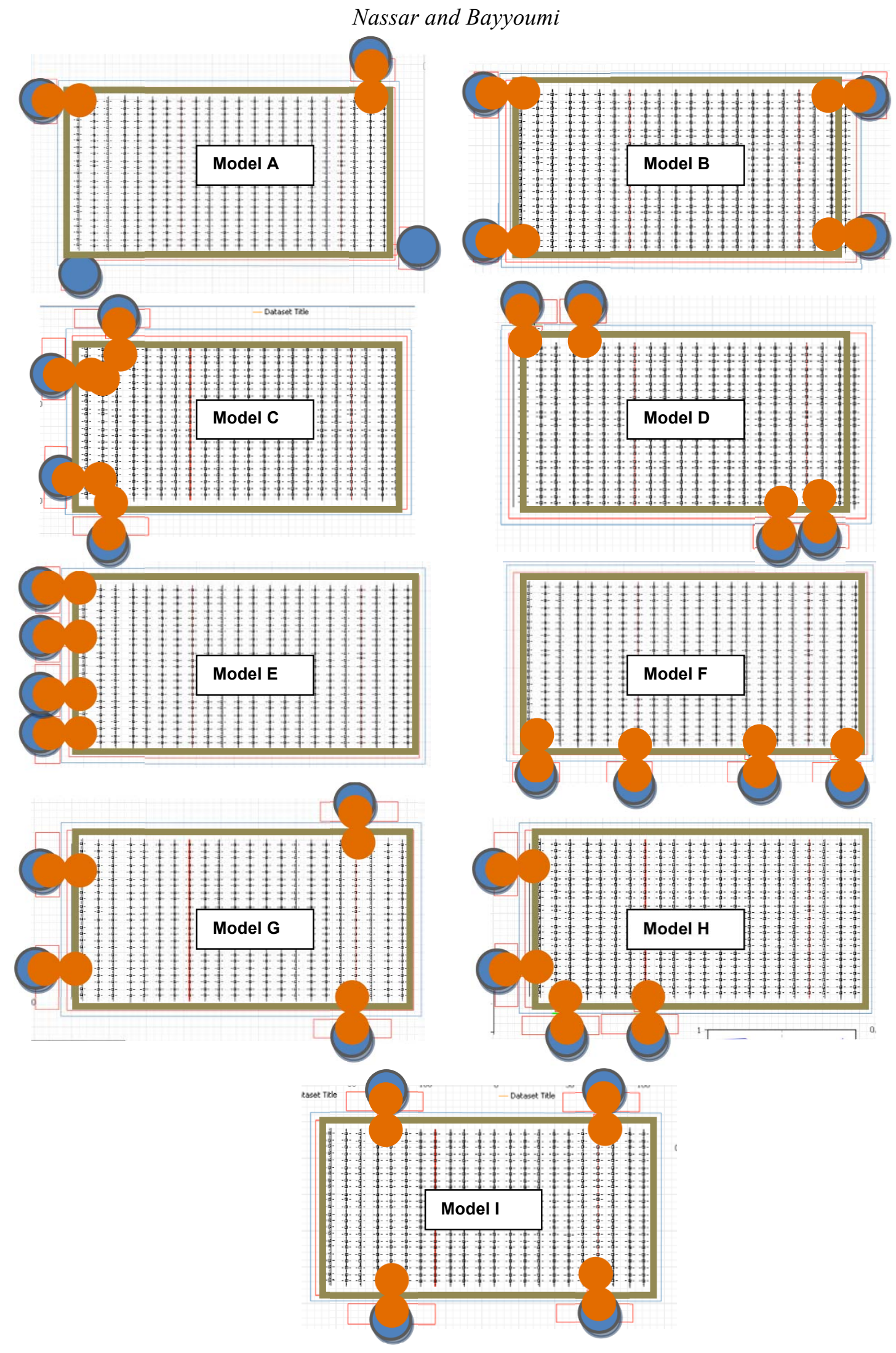

Figure 3: The nine exit configurations considered 


\section{Nassar and Bayyoumi}

\section{SIMULATING MOSQUE EGRESS BEHAVIOR}

The literature shows several models used to predict and simulate pedestrian and occupant movements by analyzing statistical data of the distributions of queues in urban and architectural spaces (Older 1968; Stilitz 1969; Sandahl and Percivall 1972). (Borgers and Timmermans 1986a, 1986b) attempted to simulate pedestrian flows on a macro scale, while (Langton 1995) simulated pedestrian flow using artificial life. Agent-based simulations have also been developed, where agents respond to others in their vicinity (Schelling 1978; Axelrod 1997). Furthermore, analogies of pedestrian movement to common physical phenomena such as fluids and gas kinetics have been proposed and tested (Henderson 1971, 1974; Helbing 1995).

One of the most promising pedestrian/occupant movement models is the so called "Social Force Model". Since its publication in "Nature" this model (Helbing et al. 2000), developed by Helbing and his co-workers at Stuttgart and therefore is sometimes referred to as the HMFV Model (Helbing-MolnárFarkas-Vicsek), have gained popularity among researchers. The model is based on analogies between social and physical forces (Helbing 1991; Helbing and Molnar 1995). In this model, the patterns of walking are described as if they would be subject to 'social forces' (Helbing and Molnar 1997). These 'forces' are not directly exerted by the pedestrians' personal environment, but they are a measure for the internal motivations of the individuals to perform certain actions (movements).

This study utilized a commercial software (Anylogic) to model the occupant/pedestrian behavior. Anylogic utilizes the social force model to simulate occupant movement and furthermore allows users to customize the behaviors' of the virtual occupant/pedestrian agents to model specific actions using Java code. The model developed in this research utilized that feature to model a number of agent behaviors that affect the performance of the various exit configurations.

- Arrival behavior. Although not directly part of the simulation model developed the arrival of the occupants will affect the egress since the occupants will likely place their shoes next to the arrival door and would likely egress from the same door as well. Similarly the parking area location in relation to the egress door will have a similar effect.

- After-prayer behavior. Rarely due worshippers exit the prayer hall directly after the prayer but instead they remain for a while for after-prayer supplications or for after-prayer sunna prayers (extra prayers). It is more likely that the first rows worshippers will be the last to leave the prayer hall.

- Shoe-pick up. The model considers the shoe placement and relationship to selection of egress door. Also the model considers the blocking that may occur due to shoe wearing at the egress door

- In addition the model considers social congregations inside and outside the mosque hall after the prayers.

The Anylogic program libraries used in this model are pedestrian library, Presentation and the General library. Modeling first started by creating the walls and doors by using poly-line from presentation library. These lines were used to represent the prayer hall walls and exits. A 500 occupant capacity was used and java code was added to emulate each of the behavior discussed above. For example we used custom variables and functions to define that occupants move towards exits with minimum density in front of them as:

pedSelectOutput.set_chance1(viewArea2.density()); 


\section{Nassar and Bayyoumi}

This function is used inside the appropriate input box in the Anylogic interface, while others were developed in external java scripts. Figure 4 shows a sample of the model and the interface of Anylogic.

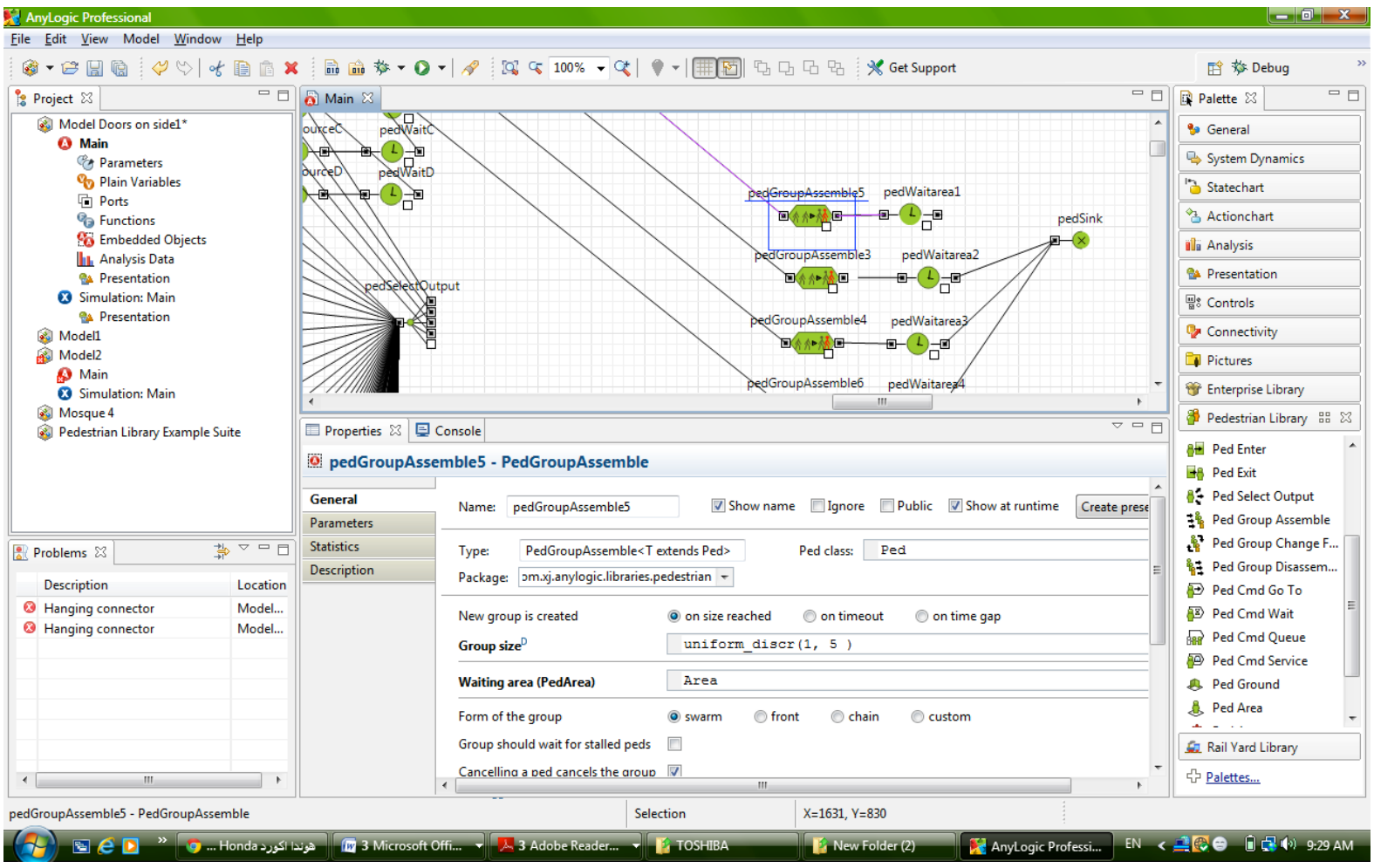

Figure 4: A sample of the model and the interface of Anylogic

The main focus of this study is to find out the optimum doors' orientation which depends on the mosque design and the various exit location configurations. The "optimum" here refers to various performance criteria; namely, the total exit time, the flow rates through the various exists and, the densities inside and outside the mosque exists. These will be explained in more detail next.

\section{RESULTS}

In order to assess which of the nine exit configurations are the most favorable in terms of egress, a number of simulation experiments were conducted. For each of the nine models a 100 replications were conducted and results were extracted from the simulations as shown in figure 5. In order to compare the nine different configurations presented in figure 3, some performance measures are needed. Specifically, 3 main performance models were considered; namely the total egress time for the 500 occupants, the average density inside mosque and the average density outside the mosque. From the results shown in figure 5 , it can be seen that alternative Model F is the best option. Alternative F, with doors placed to one side of the prayer hall results in the lowest total egress time as well as having the lowest average occupant density inside and outside the mosque prayer hall. This is mainly perhaps due to the nature of the prayer activity at the mosque as explained earlier, which allows worshippers the flexibility to egress as well as allowing simultaneously for others to congregate inside the prayer hall. 


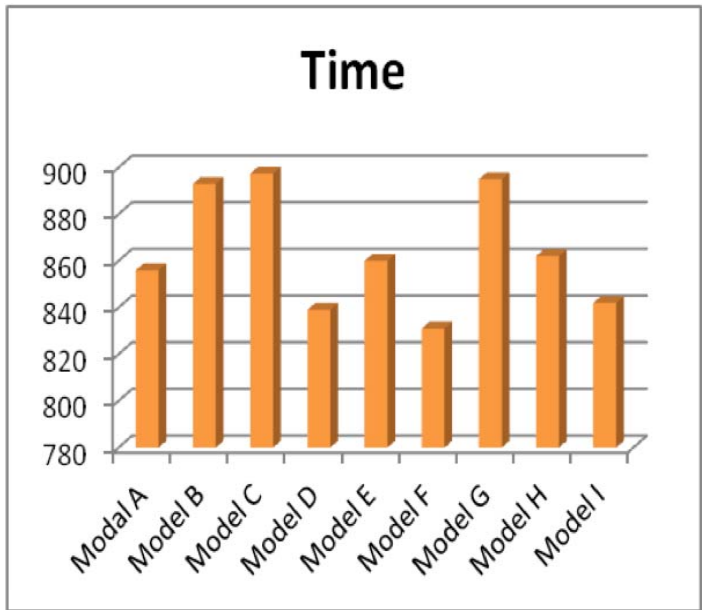

The total time

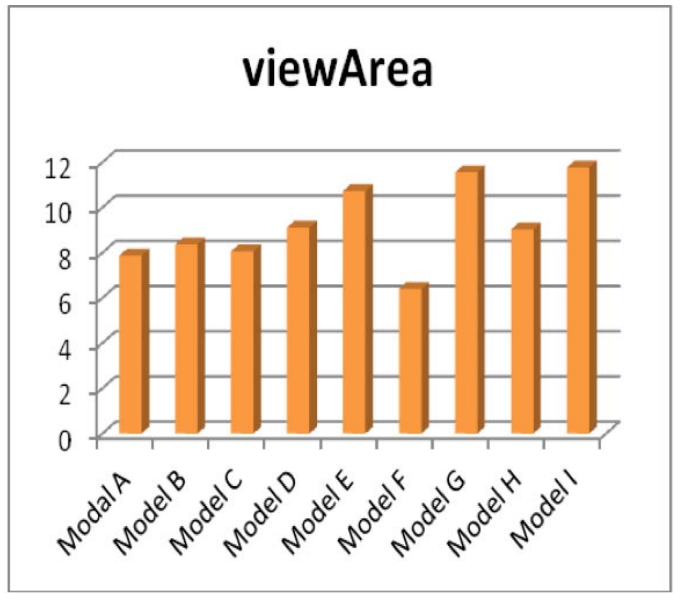

Average Density inside of the doors

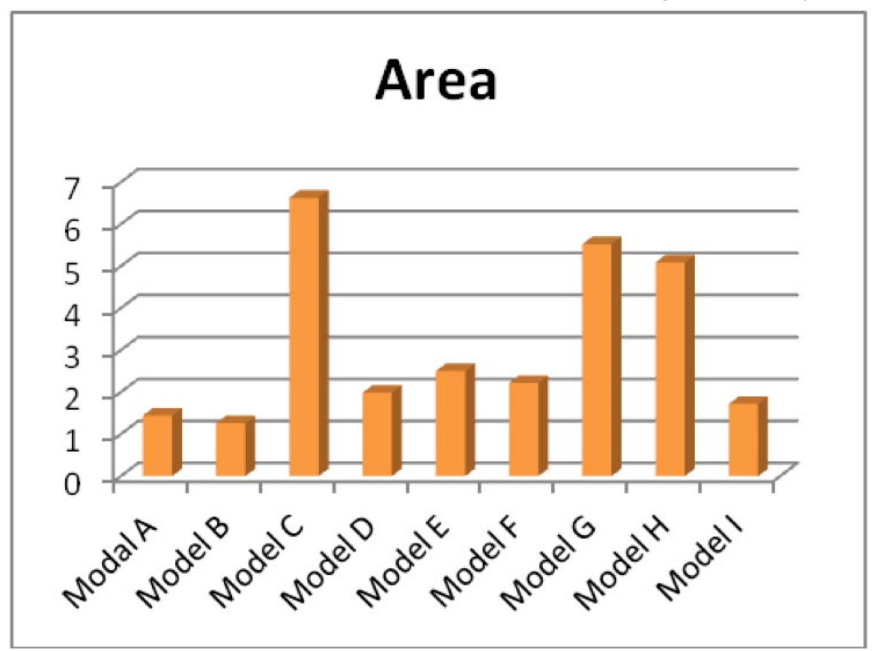

Average Density outside of the doors

Figure 5: The results obtained from the model

\section{CONCLUSIONS AND RECOMMENDATIONS FOR FUTURE WORK}

This paper presented a study into the best configuration of mosque exits to facilitate the egress of worshippers from the prayer hall. The study developed an agent based model that accounts for occupant behavior in the prayer hall and experimented with different exit configurations. It was found that placing all the exits on one side is more efficient in terms of reducing the egress time and reducing the occupant densities in front of the doors and inside the exit doors. Several extensions of this work are in progress. It is very important to extend the work described here to perform a parametric study to investigate the effect of the different parameters on the results of the simulation. Parameters such as egress conditions, after prayer waiting times, mosque size and occupant loads need to be assessed. In addition the results need to be verified from actual data collected from real mosques. 
Nassar and Bayyoumi

\section{REFERENCES}

Axelrod, R. 1997. "The Dissemination of Culture: A Model with Local Convergence and Global Polarization", Journal of Conflict Resolution, 41, 203-226.

Borgers, A., and H. Timmerman 1986b. "A Model of Pedestrian Route Choice and Demand for Retail Facilities within Inner-City Shopping Areas". Geographical Analysis, 18, 115128.

Borgers, A., and H. J. P. Timmermans. 1986a. "City Centre Entry Points, Store Location Patterns, and Pedestrian Route Choice Behaviour: A Microlevel Simulation Model”. SocioEconomic Planning Sciences, 20, 25-31.

Helbing D. and P. Molnar. 1995. "Social force model for pedestrian dynamics". Physical Review E, Vol. 51, No. 5, pp. 4282-4286.

Helbing D., 2001. "Traffic and related self-driven manyparticle systems". Reviews of Modern Physics, Vol. 73, No. 4, pp. 1067-1141.

Helbing D., I. Farkas I., and T. Vicsek. 2000. "Simulating dynamical features of escape panic". Nature, Vol. 407, pp. 487-490.

Henderson, L. F. 1971. "The Statistics of Crowd Fluids”. Nature, 229, 381-383.

Henderson, L. F. 1974. "On the Fluid Mechanics of Human Crowd Motion”. Transportation Research, 8, 509-515.

Langton, C. G. (Editor) 1995. Artificial Life: An Overview, MIT Press, Cambridge, MA

Older, S. J. 1968. Movement of Pedestrians on Footways in Shopping Streets, Traffic Engineering and Control, 10, 160-163

Sandahl, J., and Percivall, M. 1972. "A Pedestrian Traffic Model for Town Centers". Traffic Quarterly, $26,359-372$.

Schelling, T. S. 1978. Micromotives and Macrobehavior, W. W. Norton and Company, New York.

\section{AUTHOR BIOGRAPHIES}

KHALED NASSAR is an associate professor at the American University in Cairo (AUC). Prior to joining AUC, he was on the faculty of Bradley University in Peoria, Illinois, the University System of Maryland, as well as the chair of the department of architectural engineering at the university of Sharjah. He has taught and conducted research projects for the Illinois department of transportation and Caterpillar Inc, as well as NSF. He received a Ph.D. from Virginia Tech and worked for several years in the building industry. He has had several years of teaching experience in field of construction and architecture. His research interest includes computer applications in design and construction as well as simulation and visualization. His email address is $<$ knassar@aucegypt.edu $>$.

AHMED BAYYOUMI is a research assistant at the American University in Cairo (AUC). His expertise is in traffic modeling and design and has worked in Saudi Arabia and Egypt on a number of transportation and traffic related problems. 